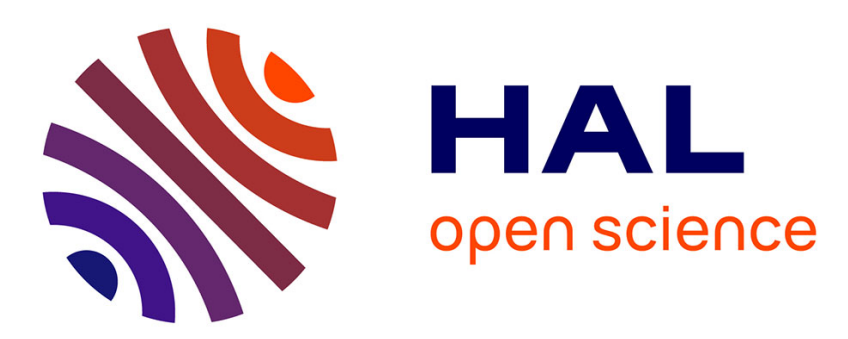

\title{
Towards Generation of Ambiguous Situations in Virtual Environments for Training
}

\author{
Azzeddine Benabbou, Domitile Lourdeaux, Dominique Lenne
}

\section{To cite this version:}

Azzeddine Benabbou, Domitile Lourdeaux, Dominique Lenne. Towards Generation of Ambiguous Situations in Virtual Environments for Training. 13th European Conference on Technology Enhanced Learning (EC-TEL 2018), Sep 2018, Leeds, United Kingdom. pp.631-635, 10.1007/978-3-319-985725_61. hal-01982271

\section{HAL Id: hal-01982271 https://hal.science/hal-01982271}

Submitted on 21 Jun 2021

HAL is a multi-disciplinary open access archive for the deposit and dissemination of scientific research documents, whether they are published or not. The documents may come from teaching and research institutions in France or abroad, or from public or private research centers.
L'archive ouverte pluridisciplinaire HAL, est destinée au dépôt et à la diffusion de documents scientifiques de niveau recherche, publiés ou non, émanant des établissements d'enseignement et de recherche français ou étrangers, des laboratoires publics ou privés. 


\title{
Towards generation of ambiguous situations in virtual environments for training
}

\author{
Azzeddine Benabbou ${ }^{1}$, Domitile Lourdeaux ${ }^{1}$ and Dominique Lenne ${ }^{1}$ \\ ${ }^{1}$ Sorbonne universités, Université de technologie de Compiègne, CNRS UMR 7253 Heudiasyc \\ 57 avenue de Landshut - 60203 Compiègne Cedex, France \\ \{azzeddine.benabbou - domitile.lourdeaux - dominique.lenne\}@hds.utc.fr
}

\begin{abstract}
Ambiguous situations are referred to as situations that are open to more than one interpretation. Our objective is to train individuals to handle this kind of situations using Virtual Environments for Training (VET). However, producing a large panel of ambiguous situations adapted to the learner requires serious authoring efforts. To address this issue, we propose to generate these situations automatically without having to write them beforehand.
\end{abstract}

Keywords: Ambiguity, Scenario generation, Virtual Environments, Training

\section{Introduction}

Critical situations can be defined as complex and dynamic situations, often unexpected and difficult to anticipate. These situations are characterized by several dimensions such as ambiguity [1]. This latter refers to situations where the state of the world is subject to different interpretations. In complex domains, especially when the safety of the self and the others is concerned (e.g. healthcare, driving), individuals need to be trained to identify, handle and anticipate such situations. Failing to handle these situations can lead sometimes to disastrous consequences. This is why training in genuine conditions is not always possible. Therefore, using VET can help in that matter. Our pedagogical objective here, is to complete the initial training of the learners. We suppose that they have already acquired the needed technical skills, and we aim to train them to make use of their non-technical skills (e.g. communication, situation awareness). The purpose, in particular, is to train them to reduce the ambiguity in such situations in order to be able to make the most appropriate decisions. To provide such training, we need to confront the learners to various ambiguous situations. However, the complex nature of the domains stands against the possibility of writing all the possible situations beforehand. Especially if we want to have a control on the simulation and present "explicable" situations that enable us to debrief with the learners afterwards. One way to address this issue is to generate these situations automatically. This paper is organized as follows: In section 2, we present a quick review of the literature on ambiguity. Then, in section 3, we list some related work. Finally, in section 4, we detail the ambiguity generation process. 


\section{Ambiguity}

The Merriam-Webster dictionary defines ambiguity as " $a$ word or expression that can be understood in two or more possible ways". This might be the most common definition that comes to people's mind when ambiguity is referred to. In his famous paper in 1961, Ellsberg [2] defined ambiguity as "a quality depending on the amount, type, reliability and 'unanimity' of information, and giving rise to one's degree of confidence in an estimate of relative likelihoods". This description considers the information as the core item of ambiguity. It is also the case of several conceptions of ambiguity in statistics, economics and risk assessment. Camerer and Weber [3] for example, defines ambiguity as "uncertainty about probability, created by missing information that is relevant and could be known". Ambiguity is also referred to as epistemic uncertainty [4]. This latter comes from the lack of information. Thus, unlike the aleatory uncertainty, it is reducible. Blockley [5] defines ambiguity as a mix of Fuzziness and Incompleteness that corresponds to the epistemic dimensions of his space. While these previous conceptions of ambiguity focus on information, Gaver et al. [7] distinguish three broad classes of ambiguity: (1) Ambiguity of information that finds its source in the artefact itself, (2) Ambiguity of context that finds its source in the sociocultural discourses that are used to interpret it and (3) Ambiguity of relationship that find its source in the interpretative and evaluative stance of the individual. In this paper, we focus on the generation of the first class of ambiguity. It emerges mainly from the remediable lack of relevant information and/or the poor quality of the available information. In healthcare for instance, an example for such ambiguity would be a doctor facing a situation where the medical record of the patient says that $\mathrm{s} / \mathrm{he}$ is not allergic to a given substance, but manifested anyway an allergic reaction when this substance was administrated.

\section{Related work}

Cottone et al. [8] conducted a study using a virtual city to investigate how people cope with ambiguity using different means of communication (face-to-face, chat and phone). The participants' goal was to meet at a specific place of their choice. The virtual city was purposely designed to contain similar places to create ambiguity. Mantovani et al. [9] investigated the suitability of virtual environments for safety training, in particular in capturing ambiguity. The participant's goal was to find a way out from a virtual library using two types of emergency signs. A particular group faced an ambiguous situation where there was a red ribbon blocking the exit. The participants did not know if they should respect it in this emergency context and find another way out, or they should pass over it. In military field, Raybourn et al. [10] created a multiplayer game to train Special Forces Team Leaders to cope with "uncertain" scenarios such as ambiguous situations. In all these systems, ambiguous situations are written beforehand. As far as complex domains are concerned, especially when the learner has to be confronted to a large panel of situations, this approach is doomed to fail. Our ambition is to design an original system that generates automatically ambiguous situations. To our best knowledge, there is no system in the literature that adopts such approach. 


\section{$4 \quad$ Ambiguity generation}

Gaver et al. presented several tactics to create ambiguity of information. In this section, we detail four ways, inspired by these tactics, and illustrate them with examples.

Using incomplete representation to emphasize uncertainty by hiding relevant information that is crucial for determining which action to take. Let $A=\left\{a_{1}, \ldots, a_{n}\right\}$ be the possible actions and $\left\{P_{1}, \ldots P_{n}\right\}$ be respectively the sets of their preconditions such as their intersection is not empty. We define the function $f(A)$ which input is a set of actions A. The function output is the symmetric difference of the preconditions of the actions. This corresponds to the relevant information that needs to be hidden.

$$
f(A)=\left(P_{1} \cup P_{2} \cup \ldots \cup P_{n}\right) \backslash\left(P_{1} \cap P_{2} \cap \ldots \cap P_{n}\right)
$$

For example, let us consider the following actions: $a_{1}=$ "Pass at green light" and $a_{2}=$ "Stop at red light" with the following preconditions: $P_{1}=$ \{"TrafficSign is Light", "Light hasColor Green" $\}$ and $P_{2}=\{$ "TrafficSign is Light", "Light hasColor Red" \}. The common precondition of the two actions is that there must be a traffic light. The relevant information here is the color of the light. As long as this information is unknown, this situation can be interpreted, at least, in two ways: either the light is green, therefore the action "Pass at green light" is relevant, or the light is red, therefore the action "Stop at red light" is relevant. Thus, according the output of this function, the view to the traffic light must be obstructed in the simulation. Using fuzzy information to emphasize uncertainty by casting impreciseness or vagueness in information. We define the fuzzifier function $f(A i, \varepsilon)$ which inputs are an assertion $A i$ and a threshold $\varepsilon \in[0,1]$ that represents the degree of fuzziness to go below it. The output of the function is a set of assertions $A$ that correspond to a world state that needs to be reached. For example, the main character is followed by a Car. To make this information fuzzy we can provoke a fog:

$$
f(\text { "LearnerCar BehindObject Car", 0.5) }=\{\text { "Wheather Is Foggy" }\}
$$

Casting doubt on sources to provoke independent assessment by adjusting the world state in order to reduce the credibility of the sources. In a fuzzy representation, each source of information has a degree of credibility. We define the function $f(s, \varepsilon)$ which inputs are the source $s$ (e.g. object, character) and a threshold $\varepsilon \in[0,1]$ that represents the degree of credibility to go below it. The output of the function is a set of assertions $A$ that correspond to a world tate that needs to be reached. For example, the main character wants to ask a pedestrian for directions. One way to reduce this source's credibility would be to make this pedestrian drunk:

$$
f(\text { "Pedestrian", 0.2) }=\{\text { “Pedestrian isDrunk true" }\}
$$

Exposing inconsistencies to create a space of interpretation by providing information that is conflictual with the learner's mental model. We define the function $f(m)$ which input is the mental model of the learner $m$ (set of assertions). The output is the set of assertions that are contradictory with $m$. For example, if the traffic light is red, one way to create a conflictual situation is to turn on the green light too. 
$f(\{"$ TrafficLight Color Red"\}, 0.1) = \{"TrafficLight Color Green" $\}$

\section{Discussion and evaluation}

This conceptual proposition is in need of evaluation. Firstly, we need to evaluate that the generated situations are truly ambiguous. To achieve that, we propose to confront individuals to both generated and scripted (written beforehand) situations. The comparison between how these two types of situations are perceived by the individuals will give us an indication about how successful is the system in generating ambiguity. Secondly, we need to investigate how confronting individuals to ambiguous situations improves their non-technical skills. To do so, we propose to study how they reduce the ambiguity before and after confronting them to a large panel of ambiguous scenarios.

\section{References}

[1] J.-M. Burkhardt, V. Corneloup, C. Garbay, Y. Bourrier, F. Jambon, V. Luengo, A. Job, P. Cabon, A. Benabbou, and D. Lourdeaux, "Simulation and virtual reality-based learning of non-technical skills in driving: critical situations, diagnostic and adaptation," in IFAC-PapersOnLine, 2016, vol. 49, no. 32, pp. 66-71.

[2] D. Ellsberg, "Risk, Ambiguity, and the Savage Axioms," Q. J. Econ., vol. 75, no. 4, p. 643, Nov. 1961.

[3] C. Camerer and M. Weber, "Recent Developments in Modelling Preferences: Uncertainty and Ambiguity," J. Risk Uncertain., vol. 5, pp. 325-370, 1992.

[4] F. O. Hoffman and J. S. Hammonds, "Propagation of uncertainty in risk assessments: the need to distinguish between uncertainty due to lack of knowledge and uncertainty due to variability.," Risk Anal., vol. 14, no. 5, pp. 707-12, Oct. 1994.

[5] D. Blockley, "Analysing uncertainties: Towards comparing Bayesian and interval probabilities'," Mech. Syst. Signal Process., vol. 37, no. 1-2, pp. 30-42, May 2013.

[6] O. Renn, "White Paper on Risk Governance: Toward an Integrative Framework," in Global Risk Governance, Dordrecht: Springer Netherlands, 2008, pp. 3-73.

[7] W. W. Gaver, J. Beaver, and S. Benford, "Ambiguity as a resource for design," in Proceedings of the conference on Human factors in computing systems - CHI '03, 2003, no. January 2003, p. 233.

[8] P. Cottone, L. Pieti, V. Schiavinato, D. Soru, M. Martinelli, D. Varotto, and G. Mantovani, “'solving' ambiguity in the virtual space: Communication strategies in a collaborative virtual environment," Cogn. Technol. Work, vol. 11, no. 2, pp. 151-163, Jun. 2009.

[9] G. Mantovani, L. Gamberini, M. Martinelli, and D. Varotto, "Exploring the Suitability of Virtual Environments for Safety Training: Signals, Norms and Ambiguity in a Simulated Emergency Escape," Cogn. Technol. Work, vol. 3, no. 1, pp. 33-41, Feb. 2001.

[10] E. M. Raybourn, "Adaptive Thinking \& Leadership Simulation Game Training for Special Forces Officers," in Interservice/Industry Training, Simulation, and Education Conference, 2005. 